\title{
Are letter codes always activated?
}

\author{
SETH N. GREENBERG \\ Union College, Schenectady, New York
}

\begin{abstract}
This investigation assesses whether a word's constituent-letter codes are activated when wholeword processing is encouraged, as well as when letter processing is encouraged. In Experiments 1 and 2, word primes were followed by a target item that had to be named. The target was a word, a constituent letter that had appeared in the prime, or a nonconstituent letter that had not appeared in the prime. The measure of constituent-letter activation was the difference in letter-naming latency between constituent and nonconstituent letters. Presumably, if constituent letters are named faster, letters are being activated by the words in which they appear. To encourage either whole-word or letter analysis during the processing of the priming word, the proportion of word versus letter targets was systematically varied. When the proportion heavily favored letter targets, constituent letters were named faster than their nonconstituent controls. However, a constituent-letter (vs. a nonconstituent-letter) advantage was not obtained when the proportion favored word targets. Experiment 3 replicated the effect with a priming task that required a discrimination response, instead of a naming response. Thus the results suggested that the activation of constituent-letter codes need not take place during the processing of words, but occurs only when letter analysis is stressed by the task.
\end{abstract}

The issue examined in the present study was whether the processing of a briefly exposed single word necessarily activates the codes of its constituent letters. Models of word recognition that claim that recognition rests on the preliminary identification of constituent letters (e.g., Besner, Davelaar, Alcott, \& Parry, 1984) assume that word analysis will lead to activation of letter codes in memory. However, even models that suggest that wholeword codes are accessed directly (without letter-mediated activity) acknowledge that an extended analysis of a word will generally yield information about a word's constituent letters (Johnson, 1986). An exception to this position is the unitization model proposed by Drewnowski and Healy (1977), who claimed that the processing of familiar words begins with the analysis of both word patterns and constituent letters. However, once the unitized pattern code is accessed, further processing at the letter level is halted. Thus, the letters in the words never activate their cognitive codes as letters alone. Recently though, Healy, Oliver, and McNamara (1987) amended the unitization model to reflect their finding that familiar words in multiword displays concealed their letters, whereas familiar words presented in isolation did not. Healy et al. argued

\footnotetext{
The research for this article was supported by the Union College Research Fund. A portion of it was presented at the meeting of the American Psychological Association, August 1984, in Toronto. I wish to acknowledge Francis Frederighi, Becky Lumpkin, Etti Merkine, Lynda Richards, and Tina Sciocchetti for their help. Natalie Oransky conducted the initial investigations, and Frank Vellutino also helped throughout. Lester Krueger, Janet Proctor, and an anonymous reviewer made thoughtful comments and suggestions. The article was completed while the author was a visiting research associate at the Institute of Information Processing and Decision Making at Haifa University. Requests for reprints should be sent to Seth N. Greenberg, Department of Psychology, Union College, Schenectady, NY 12308.
}

that multiword displays drive subjects to move to succeeding words before letter identification is achieved, whereas single-word displays permit the analysis of letters to reach completion.

Although models that argue for the priority of wordpattern codes can accommodate words' activating their constituent letters, these models also suggest that words may be accessed without activation of their letter codes. Presumably, the reader proceeds with letter-level analysis of isolated words only when such an analysis is useful. Although Healy et al. (1987) did not make it explicit, it follows from their discussion that the activation of constituent letter codes is not automatic. The reader must engage or provide the resources for the mechanism that accesses cognitive codes for letters. In contrast, models that argue that preliminary letter identification is essential to word recognition claim that constituent-letter codes must be activated during word analysis (e.g., Besner et al., 1984). Thus, the goal of the present study was to determine whether word-level codes could be processed without letter-level codes' also being activated.

By encouraging subjects to focus on either the whole word or its component letters, we can learn whether letter activation is normally a consequence of the processing of words, or whether it occurs only when letter identification is central to the task. This strategy has actually been used by other investigators to explore whether the pattern of accessing a word's various cognitive units is fixed or flexible. However, the few studies that have investigated this question have revealed little about whether letters are or are not routinely activated during the processing of words.

Work by Smith (1979), and more recently by Smith, Theodor, and Franklin (1983), as well as by Kaye and Brown (1985), has provided some support for the notion 
that access to a whole word's pattern code is neither fixed nor automatic. Briefly, they have discovered that the ability of a word to prime a semantic associate is inhibited when letter processing (via a letter search of the prime) is encouraged. The results indicate that where information about a word's constituents is required, semantic features are not accessed. While these results suggest that the activation of a word's pattern code (or a word's semantic properties) is not necessarily compatible with the retrieval of constituent-letter representations, they provide no direct evidence that letter-code activation is inhibited by word-pattern processing.

In one study that did directly address the issue of lettercode activation, Proctor and Healy (1985) found no indication that letter information was affected by task demands, that is, whether subjects were encouraged to focus on letters or words. The subjects had trouble finding the letter $t$ in the word the, regardless of whether or not they had been instructed to read the words in a passage as they searched it for the target letter. Unfortunately, as Healy et al. (1987) have pointed out, a letter search through multiword displays discourages letter analysis. Thus, Proctor and Healy's search procedure was not optimal for determining whether it was possible to process words without activating their letter codes. Clearly, to test whether accessing word codes normally produces activation at the level of letter codes, one must begin with a word-recognition task that discloses letter activation. In general, tasks that present isolated words provide a better opportunity for investigating the issue (Healy et al., 1987). Hence, in the present investigation, I employed a procedure (with isolated word displays) that had already provided direct evidence of letter-code activation during the processing of words (Greenberg \& Vellutino, 1984, 1988).

In the current study, a word or nonword prime appeared briefly, followed by a letter that either did or did not appear in the prime. Time to name constituent and nonconstituent letters was compared in Experiments 1 and 2, and the time to discriminate constituent and nonconstituent letters from nonletter characters was assessed in Experiment 3. Presumably, if word constituents were activated upon presentation of a given word, then it would take less time to process a letter when it was primed by a word in which it appeared (following the logic of Posner \& Snyder, 1975, and Tanenhaus, Flanigan, \& Seidenberg, 1980). If, in contrast, words were exclusively processed as unitary encodings, then no priming advantage would occur. Since the present subjects did not have to make any decisions about whether a letter appeared in a prime (i.e., they responded only to the letter target), this present task would also reduce postperceptual and memorial influences (see Greenberg \& Vellutino, 1988).

To test whether letter codes are always activated by whole-word codes, or whether their activation is impeded by attention to whole-word codes, the constituent priming procedure was combined with an expectancy manipu- lation suggested by the work of Carr, Davidson, and Hawkins (1978) (see also Tweedy, Lapinski, \& Schvaneveldt, 1977). Carr et al. varied the proportion of nonsense strings and words serving as fillers in trial blocks. Presumably, subjects would be prone to consider information at a word level in a block dominated by word fillers. In contrast, a block dominated by nonsense fillers ought to entice subjects to treat all strings as collections of letters. Since Greenberg and Vellutino have demonstrated that words prime their constituent letters when letters are the primary targets, the concern here was whether letter priming would still occur when whole words replaced letters as the dominant target.

Finally, if our study should reveal that the letter priming advantage occurred where letters were the dominant target, but not where words were dominant (i.e., the word-expectancy condition), its design would permit us to assess whether the word-expectancy condition inhibited preparation of letter responses (a mental set effect), or affected some other process involved in letter-code activation. Presumably, if the word-expectancy condition adversely affected the preparation of letter responses, then the responses to absent letters (not in primes) would be slower in the word-expectancy condition than in the letterexpectancy condition. If responses to absent-letter targets were not affected by expectancy, then a disruptive effect of word expectancy on the letter-priming advantage could not be attributed to a set effect.

\section{EXPERIMENT 1}

Experiment 1 was designed to investigate letter priming by words, under different levels of task-induced expectation. To accomplish this aim, Experiment 1 varied the relative proportion of letter and word targets in a trial block. In the letter-expectancy (LE) condition, singleletter targets occurred in $80 \%$ of the trials and word targets in $20 \%$. In the word-expectancy (WE) condition, word targets appeared in $80 \%$ of the trials and single-letter targets in $20 \%$.

\section{Method}

Subjects. Forty-eight undergraduate volunteers at Union College were paid \$2 each for participating in Experiment 1. English was the primary language spoken by each.

Materials. The word primes for the letter targets were always four letters long. Each word was used once to prime a present letter and once to prime an absent letter. Thus, 20 words were employed, twice each, over the $\mathbf{4 0}$ word-letter trials. The target letters were G, N, B, D, M, E, R, F, and H. Not all the letters appeared equally often as targets in the present and absent sets, but the two sets had a $90 \%$ overlap. The priming words used in word-word trials were, with few exceptions, also four letters (seven were five letters and four were three letters), and the targets in these trials were primarily four letters long (four were five letters and two were three letters). The associated pairs were culled from various association norms.

Procedure and Design. Prior to participating in the actual experiment, the subjects were given 20 practice trials that mimicked 
the types of trials (for word and letter targets) presented in the experiment itself. The subjects were assigned randomly to either the LE or the WE condition. In each condition, each subject received four trial blocks of 50 trials each, or 200 trials in all. A trial always consisted of a prime displayed for $150 \mathrm{msec}$, followed immediately by a 30-msec pattern mask (@@@@@), and finally a target. The type of prime and target presented in a particular trial depended on the subject condition and trial block. For the LE condition, the first three trial blocks always began with a prime consisting of five consecutive question marks (?????), and the target was a single digit number from 1 to 9 . The presentation of digit targets was random across the three blocks. The final block for the LE condition consisted of $\mathbf{4 0}$ trials in which word primes were followed by single-letter targets and 10 additional trials in which word primes were followed by word targets. The 40 word-letter trials provided 10 trials in which the target letter appeared in its prime's initial position (present), 10 trials in which the target letter appeared in its prime's final (i.e., fourth) position (present), and 20 trials in which targets followed primes in which the target letter did not appear (absent). In the absent trials, primes in the present condition were reassigned to the target letters. For the purpose of data analysis, words used to prime first-position letters in the present condition were designated as first-position primes for the absent condition as well. Similarly, last-position primes in the present condition were designated last-position primes for the absent conditions. In the 10 word-word trials, words primed moderate-to-high associate-word targets (e.g., DOGS-CATS). The 50 trials in the final block were randomized with the stipulation that word-word trials be distributed evenly throughout the block.

Subjects in the WE condition received four blocks, each block consisting of 40 word-word trials and 10 word-letter trials. As was the case with the LE condition, word-word trials used semantically related primes and targets. The 10 word-letter trials per block were a mixture of present (initial and final position) and absent trials, with no less than two initial, two final, and four absent trials per block. Over the four WE blocks, the same 40 word-letter trials used in the LE final block appeared.

The subject's task in each trial, regardless of the condition, was to name the target as soon as possible, without making an error. Thus, depending on the trial, the subject named either a digit, a letter, or a word. In the WE condition, subjects should have expected mainly word targets, whereas in the LE condition, subjects should have expected digits in the first three blocks and primarily letters in the final block. The first three blocks were used primarily to create, in the LE condition, as much fatigue and practice as in the WE condition. A problem created by the inclusion of a digitresponse block for the LE group was that this experience (i.e., single-digit responding) was then confounded with expectancy. However, since we have already demonstrated that single-letter priming occurs without a lead block of digit-responding (Greenberg \& Vellutino, 1984, 1988), we can be certain that letter-priming effects, found in the LE condition, would not be due to experience with the "warmup/fatigue"' blocks.

Apparatus. Stimuli were presented on an APS monitor controlled by an Apple $\Pi+$ computer with two disk drives. Words and letters were presented in uppercase, with all letters and characters measuring approximately $3 \mathrm{~mm}$ wide and $4 \mathrm{~mm}$ high. Spaces between letters were $1 \mathrm{~mm}$ wide. Thus, at a viewing distance of approximately $88 \mathrm{~cm}$, the visual angle subtended by a four-letter prime or target was approximately $0.97^{\circ}$. The fixation area in which the primes and targets appeared was bounded by two 30 -mm-long parallel horizontal dashed lines spaced $16 \mathrm{~mm}$ apart in the center of the screen. The prime and mask appeared in the space slightly above the center of the fixation area; the targets appeared slightly below the midpoint of the space previously occupied by the prime and mask. A trial was initiated by the subject's pressing the space bar of the computer keyboard, located directly in front of the sub- ject. Response time was measured from the time the target appeared until the subject's naming of the target was picked up by a Gerbrand's voice key. A Mountain Hardware clock in the computer measured the response time to an accuracy of $1 \mathrm{msec}$, while computer circuitry controlled the prime and mask durations.

Latencies exceeding $750 \mathrm{msec}$ or less than $250 \mathrm{msec}$ were eliminated from the analysis (such responses occurred less than once per subject). Additionally, trials in which mechanical errors occurred or subjects misread the target were also excluded. An experimenter seated behind the subject's response area noted any incorrectly named targets.

\section{Results and Discussion}

Mean correct naming latencies for target letters are reported at the top of Table 1. Errors were negligible; only 3 subjects mistook a "G" for a "9" (one trial in each case), and no subject misread more than three words. The mean percentage of errors did not exceed $1 \%$ in any word- or letter-naming condition.

As shown in Table 1, a priming advantage for letters appearing in primes (present) occurred only where letters were the expected target (the LE condition). There was a priming advantage of $18 \mathrm{msec}$ under the LE condition, but a priming disadvantage of $9 \mathrm{msec}$ for the WE condition. A three-factor analysis of variance (ANOVA) indicated that the suggested interaction of presence (present vs. absent) $\times$ expectancy (letter vs. word targets) was significant $[F(1,46)=7.86, p<.01]$. A post hoc assessment of the interaction using the Neuman-Keuls procedure indicated that the advantage of present targets over absent targets was significant $(p<.025)$ in the LE condition, while the disadvantage observed in the WE condition was not significant. Also, Table 1 shows that $a b$ sent letters were not affected by expectancy. No main effect or other interaction was significant.

The letter latency results of Experiment 1 replicated the constituent-letter priming effect demonstrated by Greenberg and Vellutino (1988). Note, however, that the previ-

\section{Table 1}

Letter-Naming Latencies (in msec) as a Function of Presence of Letter in Prime, Expectancy, and Letter Position in Prime

\begin{tabular}{|c|c|c|c|c|}
\hline \multirow{2}{*}{$\begin{array}{c}\text { Expectancy } \\
\text { Condition }\end{array}$} & \multirow{2}{*}{$\begin{array}{c}\text { Letter } \\
\text { Position }\end{array}$} & \multicolumn{2}{|c|}{ Letter in Prime } & \multirow[b]{2}{*}{ Advantage } \\
\hline & & Absent & Present & \\
\hline \multicolumn{5}{|c|}{ Experiment 1: Word Primes } \\
\hline LE & $\begin{array}{l}\text { lst } \\
\text { 4th }\end{array}$ & $\begin{array}{l}476 \\
477\end{array}$ & $\begin{array}{l}450 \\
467\end{array}$ & $\begin{array}{l}26 \\
10\end{array}$ \\
\hline WE & lst & 478 & 496 & -18 \\
\hline & 4th & 489 & 488 & 1 \\
\hline \multicolumn{5}{|c|}{ Experiment 2: Word Primes } \\
\hline LE & lst & 467 & 442 & 25 \\
\hline & 4th & 470 & 464 & 6 \\
\hline WE & lst & 505 & 501 & -4 \\
\hline & 4th & 516 & 510 & 6 \\
\hline \multicolumn{5}{|c|}{ Experiment 2: Pseudoword Primes } \\
\hline LE & lst & 508 & 474 & 34 \\
\hline & 4th & 507 & 486 & 21 \\
\hline WE & lst & 494 & 496 & -2 \\
\hline & 4th & 506 & 513 & $-\overline{7}$ \\
\hline
\end{tabular}

Note-LE = letter expectancy, WE $=$ word expectancy. 
ous work's task used letter versus nonletter character (e.g., \% or \&) discrimination instead of letter-naming. Thus, the present findings attested to the consistency of constituent-letter activation following a brief presentation of a word. More importantly, though, the present results qualified the conditions under which letter-code activation is found. Specifically, constituent-letter codes were activated where letters were the dominant (i.e., expected) target, but not where semantic associates were the dominant targets. The findings disconfirm models that assume some fixed unit of activation, particularly models advocating letters as the building units of word recognition (e.g., Besner et al., 1984; Massaro, 1975). Finally, the failure of expectation to affect absent-letter responses indicates that the manipulation of expectation was not simply influencing the preparation of letter responses.

In addition to analyzing letter-target data, an analysis was performed on word-target data. However, since the experiment was not specifically designed for such a comparison, any conclusions drawn from this analysis were compromised by the procedure (e.g., WE subjects had more practice discriminating between words and foils than did LE subjects). The analysis revealed that naming the semantic associates of the word primes was significantly slower in the LE condition than in the WE condition [501 vs. 474 msec, respectively; $t(46)=1.94, p<.05$ ]. Since the response to words was delayed where the letter targets were dominant, there was further evidence that lettercode activation did not mediate the processing of word codes.

\section{EXPERIMENT 2}

Experiment 2 used a WE condition in which a word primed itself rather than a semantic associate. Research on priming has shown that a word primes itself more quickly than it does a semantic associate, indicating that direct priming requires less processing than does semantic priming (Warren, 1977). Presumably, when subjects know a word is to be followed by itself (most of the time), they can ignore semantic information. Perhaps word analysis that need not culminate in semantic priming presents less of a barrier to letter-code activation. Tzelgov, Henik, and Friedrich (1987) found that although letter searches of primes interfered with a word's ability to prime a semantic associate, letter searches did not inhibit a word's ability to prime itself. Tzelgov et al. concluded that letter identification and semantic priming mutually competed with one another for mental resources. Similar competition does not exist when words are used to prime themselves, so it is possible that when semantic activation is not engaged, letter codes are activated. However, the same authors reported other experiments that suggested that letter information was not used when words primed themselves (see also Forster \& Davis, 1984). Other results, though, could be interpreted as indicating that letter codes are revealed by word self-primings (e.g., Evett \& Humphreys, 1981). Thus, the question of whether letter prim- ing occurs during word analysis, when semantic priming is not involved, certainly warrants further study.

Additionally, Experiment 2 included a pseudowordpriming condition. Since it is unlikely that whole unit codes exist for pseudowords (Lawry, 1980), it was of interest to know whether the expectancy variable would have an impact when pseudowords were primes.

\section{Method}

Sixty-four Union College undergraduate volunteers were paid \$3 each for participating in Experiment 2.

The method was essentially identical to the method used in Experiment 1 . However, instead of a word priming a semantically related target, it primed itself (e.g., DOGS-DOGS). The priming words and targets used in Experiment 1 were also used here. Also, a pseudoword condition was now included. Pseudowords were pronounceable, normal sequences that were unfamiliar; they were created by substituting one consonant for another in a real word, for example, HAMP. The pseudoword also primed itself, as well as present and absent letter targets. Target letters were the same as in the word condition. The WE blocks for pseudowords (read "pseudoword-expected") mimicked the structure of the WE blocks for words, and similarly the LE blocks for pseudowords matched that of the LE blocks for words. Half the subjects were assigned to the LE sequence and half to the WE sequence. Within an expectancy condition, subjects were evenly divided between those receiving word primes, and those receiving pseudoword primes.

\section{Results and Discussion}

Mean correct naming latencies for target letters in Experiment 2 are reported in the bottom portion of Table 1 . As in Experiment 1, letters and words were rarely misread (mean error percentages never exceeded $1 \%$ ). The subjects were somewhat more likely to name a pseudoword in a manner inconsistent with our determination of the correct naming (the mean error percentage in the WE condition was $1.6 \%$, but in the LE condition it was again under $1 \%$ ). In any event, the misnaming of pseudowords should not have any bearing on the critical letter-response latencies.

Table 1 shows a letter-priming advantage in the LE condition for both word and pseudoword priming. The 16msec advantage obtained with word primes is comparable to the 18-msec advantage obtained in Experiment 1. The pseudoword primes yielded a somewhat larger advantage, $27 \mathrm{msec}$. As in Experiment 1, no letter-priming advantage was obtained where letters were unexpected targets (WE condition). This was true whether words or pseudowords were primes. Finally, Table 1 reveals that, in the pseudoword priming condition, absent-letter targets were not affected by expectancy; in the word-priming condition, however, responses to absent-letter targets were slower in the WE condition than in the LE condition.

Separate analyses were performed on the word- and pseudoword-letter target data. Presence and position were repeated measures, while expectancy was a betweensubject factor. For pseudowords, present (i.e., primed) targets were named faster than absent targets $[F(1,30)=$ 7.33, $p<.01]$ and first-position targets were named faster than final-position ones $[F(1,30)=9.33$, 
$p<.005]$. Additionally, the critical expectancy $\times$ presence interaction was significant $[F(1,30)=14.40$, $p<.001]$. The word analysis yielded significant main effects for all three factors: expectancy $[F(1,30)=7.10$, $p<.025]$, presence $[F(1,30)=6.11, p<.025]$, and position $[F(1,30)=8.51, p<.01]$. Presence and position produced the same effects as in the pseudoword condition, whereas the expectancy effect reflected shorter latencies in the LE condition than in the WE condition. Also significant were the interaction of expectancy $x$ presence $[F(1,30)=4.89, p<.05]$ and the three-way interaction $[F(1,30)=4.15, p<.05]$, which reflected a stronger letter-priming advantage in the LE condition for targets that appeared in the first (vs. final) position. However, some modest priming of final-position letters did occur. A Newman-Keuls test of means showed that responses to absent targets were slower in the WE condition than in the LE condition $(p<.01)$. Finally, a combined analysis of word and pseudoword data yielded significant effects of expectancy $[F(1,60)=5.07, p<.05]$, presence $[F(1,60)=13.40, p<.001]$, position $[F(1,60)$ $=17.67, p<.001]$, and the expectancy $\times$ presence interaction $[F(1,60)=18.84, p<.001]$. There was no effect of prime (word vs. pseudoword) or interaction involving prime. In sum, all three analyses showed consistent outcomes, with the key presence $x$ expectancy interaction confirmed for both words and pseudowords.

The letter-latency results of Experiment 2 differed from those of Experiment 1, in that the priming of initial letters was significantly stronger than the priming of final letters. However, Table 1 reveals that priming was also more pronounced for initial letters (LE condition) in Experiment 1 , though not significantly so. In our earlier work (Greenberg \& Vellutino, 1988), as in the research of others who have employed different word-recognition paradigms, patterns favoring initial-letter recognition also have emerged (e.g., see Eriksen \& Eriksen, 1974; Perfetti \& McCutchen, 1982). Another difference between Experiments 1 and 2 is that in Experiment 2 absent targets primed by words were affected by expectancy. Thus, expectation may inhibit preparation for letter responses where subjects expect target words to be the same as the prime. Overall though, the results of Experiments 1 and 2 were quite similar.

Given the change in the word-word trials (as compared with Experiment 1), it follows that access to the cognitive codes of letters is difficult whether or not semantic priming takes place. In replicating the central aspect of the findings of Experiment 1 (i.e., the interaction of presence and expectancy), these data provided further evidence against routine activation of letter codes, and presumably against models that require letter identification as part of the word-recognition process (e.g., Gough, 1972; Massaro, 1975). The evidence that pseudowords behave like words suggested that orthographically normal, pronounceable strings were being processed at a supraletter level in the WE condition. Since the viability of intermediate codes (e.g., bigrams) has been demon- strated elsewhere (e.g., Greenberg \& Vellutino, 1988), it is reasonable to assume that these multiletter units may be the basis of pseudoword processing. Carr et al. (1978) argued that whereas words might be accessed based either upon stimulus-specific lexical information (e.g., Baron \& Strawson, 1976; Morton, 1969) or upon orthographic regularities associated with spelling patterns (e.g., Spoehr \& Smith, 1973), pseudowords could be accessed only via the orthographic mechanism. The fact that lexicality played no important role here implies that in the present task the orthographic mechanism may be used for the processing of both words and pseudowords.

The analysis of word-latency data for word and pseudoword conditions yielded a significant effect of expectancy $[F(1,60)=20.26, p<.001]$, but no effect of prime or interaction of prime and expectancy. The mean response times in the word condition were 433 and $538 \mathrm{msec}$ for the WE and LE conditions, respectively; in the pseudoword condition the means were 430 and $520 \mathrm{msec}$ for the WE and LE conditions, respectively. Clearly, word latencies were faster in the WE condition than in the LE condition. Thus, despite the change in word targets from semantic associates of the primes to the primes themselves, the present word-latency results were consistent with those of Experiment 1. Thus, even where targets are identical to primes, letter-code activation appears to disrupt word-code processing. These findings are contrary to those of Tzelgov et al. (1987), who maintained that letter search did not inhibit a word's ability to prime itself. Differences between the present procedure and that of Tzelgov et al. could account for the different outcomes; however, the contrasting results might also be a reminder that confounds in the present procedure (pertaining to the word data) could also explain the pattern of word-target latencies.

\section{EXPERIMENT 3}

Experiment 3 examined the issue of letter activation using a different response mode. In Experiment 3, subjects discriminated between targets and foils, and responded by pressing a button instead of by naming targets. The change was introduced primarily to test whether the expectancy $\times$ presence interaction revealed in Experiments 1 and 2 was peculiar to the naming task. Thus, if the expectancy effect upon letter activation was tied to articulation, it ought to disappear with a different mode of response.

\section{Method}

Subjects. Thirty-two Union College undergraduate volunteers were paid \$2 each for participating in Experiment 3.

Materials. Targets were uppercase consonants (B, D, C, L, N, $P, R, S, T, W$ ) and four-letter uppercase words. Primes were uppercase four-letter words of moderate-to-high frequency (mean = 304/million) (Kucera \& Francis, 1967). For each of the 10 consonants, two words were selected as primes (yielding 20 primes for single letters); the consonant appeared in only the initial position of one word and in only the final position of the other (e.g., 
PARK-P and JUMP-P). To devise prime-target pairings for the absent condition, each of the aforementioned words was re-paired with a consonant target that did not appear in it (e.g., JUMP-S). For the data analysis, absent trials were designated as either initialor final-position trials on the basis of the target's position in the present trial (e.g., since JUMP primed a final consonant $P$ in the present trial, JUMP-S was designated as a final-position absent trial). As indicated earlier, targets in the filler blocks were single digits and the prime was always ????. Foils were single nonletter keyboard characters $(<,>),(?, !, \#, *,+,=)$, and nonletter character strings generated by randomly combining four different nonletter characters.

Procedure and Design. The subjects first received 30 practice trials on the experimental task. Before a trial began, the subjects rested their thumbs on the space bar of a computer keyboard and their two index fingers on designated "target" and "foil" keys. Right-handed subjects pressed the semicolon key with the right index finger to make their "target" responses, and the letter A key with the left index finger to make their "foil" responses; left-handed subjects responded in the opposite way. Thus, all subjects made "target" responses with the dominant hand.

A trial was initiated when the subject pressed the space bar with the thumb, whereupon a priming word or priming character string (????) appeared on the computer's screen for $150 \mathrm{msec}$, followed immediately by a pattern mask (@@@@) for $30 \mathrm{msec}$ in the same location, and then by either a target or a foil centered below the prime and mask area. The target was a single digit, a single letter, or a word; the foil was either a single nonletter character (e.g., *) or a string of four varied nonletter characters (e.g., ? / *). The subject's task was to indicate as rapidly as possible, without error, whether the item following the mask was a target (a letter, digit, or word, depending on the condition) or a foil (a nonletter character or characters). The subjects rested for $3 \mathrm{~min}$ at the midpoint of each trial block and between trial blocks.

As in Experiments 1 and 2, the subjects were assigned to either the LE or the WE condition. Subjects in the LE condition received only one critical block and $0,1,2$, or 3 filler blocks of 100 trials each. Four subjects received each number of filler blocks. On each filler trial, the priming string (????) appeared first, followed by the pattern mask, and finally by either a single-digit target or a single nonletter character foil. Half of the 100 trials in each filler block were targets and half were foils. The filler block(s) always preceded the critical block.

For the critical block, in the LE condition, the prime was a word, the target was either a single letter or the same word as the prime, and the foil was either a single nonletter character or a string of four nonletter characters. Half of the 100 trials in the critical block were targets and half were foils. Forty of the $\mathbf{5 0}$ targets were letters $(80 \%)$ and only 10 were words $(20 \%)$. A comparable mixture of single nonletter characters (40) and strings (10) was used for foils. Finally, of the $\mathbf{4 0}$ letter targets, 20 had appeared in the priming word ( present), with half (10) being the priming word's initial letter and the other half $(10)$ being the prime's final letter. The other 20 letter targets had not appeared in the prime (absent).

In the WE condition, all subjects received four 100-trial blocks. In every block, the primes were words, while the targets were either words identical to the primes or single letters. Foils were single or strings of four nonletter characters. Blocks were evenly divided among target and foil trials. Within each block, 40 targets were words and only 10 were single letters. Thus, the proportion of letterto-word target trials was the reverse of that in the critical block of the LE condition. However, over the four blocks of the WE condition, a subject still received $\mathbf{4 0}$ letter trials, and, as in Experiments 1 and 2, these 40 letter trials were identical to the letter trials received by the LE subjects. Thus, WE subjects also received 20 letter-absent trials and 20 letter-present trials (10 each of initial-
Table 2

Experiment 3: Discrimination Latencies (in msec) and Error Rates for Letter Targets as a Function of Presence in Prime, Expectancy, and Letter Position in Prime

\begin{tabular}{|c|c|c|c|c|c|c|}
\hline \multirow{3}{*}{$\begin{array}{c}\text { Expectancy } \\
\text { Condition }\end{array}$} & \multirow{3}{*}{$\begin{array}{c}\text { Letter } \\
\text { Position }\end{array}$} & \multicolumn{4}{|c|}{ Letter in Prime } & \multirow[b]{3}{*}{ Advantage } \\
\hline & & \multicolumn{2}{|c|}{ Absent } & \multicolumn{2}{|c|}{ Present } & \\
\hline & & RT & $\overline{P E}$ & $\overline{\mathrm{RT}}$ & $\overline{\mathrm{PE}}$ & \\
\hline \multirow[t]{2}{*}{ LE } & $1 \mathrm{st}$ & 513 & 5.2 & 485 & 3.1 & 28 \\
\hline & 4th & 509 & 4.5 & 494 & 4.5 & 15 \\
\hline \multirow[t]{2}{*}{ WE } & lst & 501 & 8.1 & 501 & 5.0 & 0 \\
\hline & 4th & 511 & 11.8 & 516 & 8.7 & -5 \\
\hline
\end{tabular}

Note-LE $=$ letter expectancy, $\mathrm{WE}=$ word expectancy, $\mathrm{RT}=$ response time, $\mathrm{PE}=$ percentage of error rate.

and final-position letter targets). Latencies exceeding $1 \mathrm{sec}$ or less than $100 \mathrm{msec}$ were discarded, as were incorrect responses.

Apparatus. The apparatus and display conditions were the same as in Experiments 1 and 2.

\section{Results and Discussion}

Mean correct latencies and mean errors for letter-target trials appear in Table 2. Analysis of the error data yielded only a significant effect of expectancy $[F(1,30)=4.40$, $p<.05]$. Subjects made more errors in the WE condition than in the LE condition; however, the differences in mean error rates across conditions were primarily due to the performance of 2 subjects.

The latency data for letter targets were consistent with those obtained in the letter-naming task in Experiments 1 and 2 . Priming occurred only where letter targets were expected (LE), and the magnitude of the priming effect was somewhat stronger, though not significantly so, for initial than for final letters. There was a main effect of presence $[F(1,30)=4.77, p<.05]$ and a critical presence $\times$ expectancy interaction $[F(1,30)=7.48$, $p<.01]$. Thus, the findings (Experiment 3 ) demonstrated that the expectancy effect on letter priming is not dependent on the formation of an articulatory code. Moreover, Table 2 also shows that absent targets were not affected by expectancy in Experiment 3. Apparently, expectancy may not influence preparation of letter responses except where words prime themselves and a naming response is required.

The analysis of error and latency data for word targets was also consistent with the findings of Experiments 1 and 2. Error rates on word-target trials were $2.4 \%$ in the WE condition and $3.1 \%$ in the LE condition. Meanwhile, subjects responded significantly faster to words in the WE condition than in the LE condition [420 vs. $499 \mathrm{msec}$; $t(30)=2.65, p<.01$ ]. Thus, again the data suggested that the availability of word codes is also affected by expectancy.

\section{CONCLUSION}

The present study was designed to throw some light on whether the processing of a word always results in direct or indirect activation of its constituent letters. Clearly, 
the findings argue that letter-code activation depends upon whether letter units are singled out as necessary for performing the task. Where words were the most probable unit, letter codes remained dormant. Moreover, the results suggested that word analysis did not simply interfere with a subject's ability to formulate an articulatory code for a letter (Experiment 3), or to "prepare" for a letter response (illustrated by the absent data). Thus, to explain why letter codes are or are not made available, one must consider a mechanism other than response articulation or preparation.

One possibility is found in the model proposed by Johnson, Turner-Lyga, and Pettigrew (1986). Johnson et al. indicated that although perceptual detectors at a variety of levels of processing (e.g., the processing of letters and words) are automatically activated by the stimulus, it is the subsequent assignment of cognitive codes to activated detectors that determines response patterns (i.e., response time). Moreover, cognitive codes are generally assigned to higher order units rather than lower order units, because the former have greater utility (Greenberg \& Vellutino, 1988). (Such an ordering of the assignment of cognitive codes could account for phenomena such as the word-superiority effect described, for example, by Johnson, 1977.) However, in some tasks that involve the processing of words (e.g., proofreading, or the LE condition), letters have greater utility; consequently, cognitive codes for letters may be given priority. Furthermore, if the trends in the word data are reliable, then the activation of letter codes results in diminished access to wordpattern codes. Thus, in contrast to Johnson et al., here it is assumed that the order of the assignment of cognitive codes is not fixed.

Finally, it is worth noting that the present results replicate a curious inhibition effect found in earlier work (Greenberg \& Vellutino, 1984, 1988). In the earlier research, it was discovered that when subjects accessed high-frequency bigrams during the processing of words, discrimination responses to single-letter targets were modestly inhibited (there were slower latencies in the present than in the absent condition). Here, it appeared that when subjects attended to a word's whole pattern code, letter targets were also somewhat inhibited. This modest but consistent result suggests that the activation of higher order units interacts with lower order information actually to suppress letter codes before they reach consciousness. In sum, the present results indicated that letter codes are neither directly nor indirectly revealed by the processing of words, but rather are activated only where the processing of letter information is given priority over the processing of word patterns.

\section{REFERENCES}

Baron, J., \& Strawson, C. (1976). Orthographic and word-specific mechanisms in reading words aloud. Joumal of Experimental Psychology: Human Perception \& Performance, 2, 386-393.
Besner, D., Davelaar, E., Alcott, D., Parry, P. (1984). Wholistic reading of alphabetic print: Evidence from the FDM and the FBI. In L. Henderson (Ed.). Orthographies and reading: Perspectives from cognitive psychology, neuropsychology, and linguistics (pp. 121-135). Hillsdale, NJ: Erlbaum.

Carr, T. H., Davidson, B. J., \& Hawkins, H. L. (1978). Perceptual flexibility in word recognition: Strategies affect orthographic computation but not lexical access. Journal of Experimental Psychology: Human Perception \& Performance, 4, 674-690.

Drewnowski, A., \& Healy, A. F. (1977). Detection errors on the and and: Evidence for reading units larger than the word. Memory \& Cognition, 5, 636-647.

ErIKSen, B. A., ERIKSEN, C. W. (1974). Effects of noise letters upon identification of a target letter in a nonsearch task. Perception \& Psychophysics, 16, 143-149.

EvetT, L. J., \& Humphreys, G. W. (1981). The use of abstract graphemic information in lexical access. Quarterly Journal of Experimental Psychology, 33, 325-350.

FoRSTER, K. I., \& DAVIS, C. (1984). Repetition priming and frequency attenuation in lexical access. Journal of Experimental Psychology: Learning, Memory, \& Cognition, 10, 680-698.

GougH, P. B. (1972). One second in reading. In J. F. Kavanagh \& I. G. Mattingly (Eds.), Language by ear and by eye: The relationship between speech and reading (pp. 331-358). Cambridge: MIT Press.

Greenberg, S. N., Vellutino, F. R. (1984, August). Does a word activate its constituents? Component processing and reading. Paper presented at the Annual Meeting of the American Psychological Association, Toronto, Canada.

GreenberG, S. N., \& Vellutino, F. R. (1988). Evidence for processing of constituent single- and multiletter codes: Support for multilevel coding in word perception. Memory \& Cognition, 16, 54-63.

Healy, A. F., Oliver, W. L., McNamara, T. P. (1987). Detecting letters in continuous text: Effects of display size. Journal of Experimental Psychology: Human Perception \& Performance, 9, 413-426.

Johnson, N. F. (1977). A pattern-unit model of word identification. In D. LaBerge \& S. J. Samuels (Eds.), Basic processes in reading. Perception and comprehension (pp. 91-125). Hillsdale, NJ: Erlbaum.

JoHNSON, N. F. (1986). On looking at letters within words: Do we "see" them in memory? Journal of Memory \& Language, 25, 558-570.

Johnson, N. F., Turner-Lyga, M., \& Pettigrew, B. S. (1986). Partwhole relationships in the processing of small visual patterns. Memory \& Cognition, 14, 5-16.

KAYE, D. B., \& Brown, S. W. (1985). Levels and speed of processing effects on word analysis. Memory \& Cognition, 13, 425-434.

Kučera, M., Francis, W. N. (1967). Computational analysis of present day American English. Providence, RI: Brown University Press.

LAWRY, J. A. (1980). The interfering effect of word perception on letter identification. Perception \& Psychophysics, 28, 577-588.

MASSARO, D. W. (1975). Understanding language: An informationprocessing analysis of speech, perception, reading, and psycholinguistics. New York: Academic Press.

MoRTon, J. (1969). Interaction of information in word recognition. Psychological Review, 76, 165-178.

PerfetT, C. A., MCCUTCHEN, D. (1982). Speech processes in reading. In N. Lass (Ed.), Speech and language: Advances in basic research and practice (Vol. 7, pp. 237-269). New York: Academic Press.

Posner, M. I., SNyder, C. (1975). Facilitation and inhibition in the processing of signals. In P. M. A. Rabbitt \& S. Dornic (Eds.), Attention and performance, V (pp. 669-682). London: Academic Press.

Proctor, J. D., \& HeAly, A. F. (1985). A secondary-task analysis of a word familiarity effect. Joumal of Experimental Psychology: Human Perception \& Performance, 11, 286-303.

SмIтH, M. C. (1979). Contextual facilitation in a letter search task depends on how the prime is processed. Journal of Experimental Psychology: Human Perception \& Performance, 5, 239-251. 
Smith, M. C., Theodor, L., \& Franklin, P. E. (1983). The relationship between contextual facilitation and depth of processing. Journal of Experimental Psychology: Learning, Memory \& Cognition, 9, 697-712.

Spoenr, K. T., SмIтн, E. E. (1973). The role of syllables in perceptual processing. Cognitive Psychology, 5, 71-89.

Tanenhaus, M. K., Flanigan, M. F., Seidengerg, M. S. (1980). Orthographic and phonological activation in auditory and visual word recognition. Memory \& Cognition, 8, 513-520.

TWeEDY, J. R., LAPINSKI, R. H., SchVaneveldt, R. W. (1977). Semantic-context effects on word recognition: Influence of varying the proportion of items presented in an appropriate context. Memory \& Cognition, 5, 84-89.

Tzelgov, J., Henik, A., \& Friedrich, F. J. (1987). Semantic activation during word and picture recognition (Report No. 84-00050). Jerusalem: Israel-United States Binational Science Foundation.

WARREN, R. E. (1977). Time and the spread of activation in memory. Journal of Experimental Psychology: Leaming \& Memory, 3, 458-466.

(Manuscript received October 2, 1987; revision accepted for publication March 31,1988 .) 